IRA-International Journal of Education \& Multidisciplinary Studies

ISSN 2455-2526; Vol.06, Issue 02 (2017)

Pg. no. 142-155

Institute of Research Advances

http://research-advances.org/index.php/IJEMS

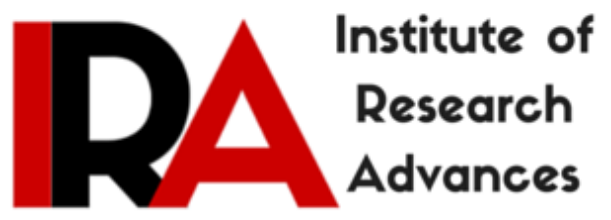

\title{
Environment and Resource Challenges Faced by Early Childhood Development Centres in Gweru Urban High Density Suburbs
}

\author{
Grace Sibusisiwe Mupondi-Masuka $^{1}$, Richard Nyika ${ }^{2}$, Phebion Kangai ${ }^{3}$ \\ ${ }^{1}$ Lingfield Christian Academy, Gweru, Zimbabwe. \\ ${ }^{2}$ Department Education and Training, Gweru Polytechnic, Zimbabwe. \\ ${ }^{3}$ Department of Teacher Education, University of Zimbabwe, Zimbabwe.
}

Type of Review: Peer Reviewed.

DOI: http://dx.doi.org/10.21013/jems.v6.n2.p1

\section{How to cite this paper:}

Mupondi-Masuka, G., Nyika, R., \& Kangai, P. (2017). Environment and Resource Challenges Faced by Early Childhood Development Centres in Gweru Urban High Density Suburbs. IRA International Journal of Education and Multidisciplinary Studies (ISSN 24552526), 6(2), 142-155. doi:http://dx.doi.org/10.21013/jems.v6.n2.p1

(C) Institute of Research Advances

\section{(oc) EY-NC}

This work is licensed under a Creative Commons Attribution-Non Commercial 4.0 International License subject to proper citation to the publication source of the work.

Disclaimer: The scholarly papers as reviewed and published by the Institute of Research Advances (IRA) are the views and opinions of their respective authors and are not the views or opinions of the IRA. The IRA disclaims of any harm or loss caused due to the published content to any party. 


\begin{abstract}
The aim of the study was to analyse the resource and environment challenges faced by Early Childhood Development (ECD) centres within Gweru Urban high density suburbs. Availability of resources and quality of the environment are crucial components in the holistic development of all children (Bruce, 2004). This study sought to establish the specific nature of resources and environment challenges currently faced by ECD centres in the Gweru urban high density suburbs. In order to establish the dimensions and nature of this phenomenon, the study adopted the mixed method approach which used interviews, questionnaires, observations and document analyses to collect data. Six (6) ECD administrators from six (6) ECD centres and thirty (30) ECD teachers from ECD centres in Gweru High Density Suburbs were purposively sampled for the study. Results showed that inadequate provision of resource and environment requirements had bedevilled centres in the high density suburbs. The centres lacked funding resulting in failure to provide a suitable environment and needed resources. The teacher-pupil ratio was as high as 1:50 which was above the 1:20 ratio stated in the Statutory Instrument 106 of 2005. The study recommended that the Ministry of Primary and Secondary Education should not allow ECD centres to operate without meeting the requirements for ECD establishment. Parents and other stakeholders were also encouraged to contribute towards funding, construction and acquisition of resources for ECD centres. The study also recommended that government and council should provide free land for the establishment of ECD centres for both public and private centres.
\end{abstract}

Key words: Early Childhood Development, ECD Centres, Environment, Resources

\title{
Background of the Study
}

The Presidential Commission of Inquiry into Education and Training (PCIET) led by Nziramasanga (1999:261) identified early childhood as, "a decisive area in the Zimbabwean education system which forms the basic principles and foundation of the country's policy of education." Traditionally, Early Childhood Education (ECE) was the responsibility of the family. At this stage, the child received primary socialisation as part of informal education offered by the family. The child was taught fundamental norms and values of society. The high demand of western education and urbanisation gave birth to the need to have early childhood education in a school set up as a way to prepare the child to fit well in a modern school system. According to the commission, child development begins at conception and learning starts at birth. It identified the first few years of a child's growth as crucial to the development of intelligence, social behaviour and personality. Nziramasanga (1999:264) states that, "the provision for Early Childhood Education and Care (ECEC) Centres have been placed high on the Zimbabwe's Vision 2020 Agenda." The Zimbabwe Programme for Economic and Social Transformation (ZIMPREST) also prioritised the need to improve the facilities of early childhood learning facilities. The 1987 Education Act Number 27 made provisions for drawing up of regulations for nursery schools. These legal frameworks gave impetus to fully flagged implementation of Early Childhood Education in many centres opened in both rural and urban areas in the country.

Zimbabwe Network of Early Childhood Development Actors (ZINECDA) (2013) states that the Ministry of Education provided each of the ten provinces in Zimbabwe with a model centre whose purpose is to shed light on ideas of ideal ECD centres in the provinces. Bernard (2005) defines a model as framework from which to build from and select portion of implementation. A model is an example from which to work from and borrow ideas for implementation. Mugweni (2011) contends that these model centres were community driven and supported by parents. This was an adherence to the Secretary Circular Number 14 of 2004 on the issue of ECD as a community based programme. The centres were intended to be provincial models which provided quality ECD education. In Midlands Province, the model ECD centre was Pamberi Nekubatana which is located in the District of Chiwundura (at Gambiza Primary School). ECD centres in the Midlands Province were expected to borrow ideas from the model in order to set-up their own standard ECD centres. ZINECDA (2013) 
emphasises that by making use of the model centres as references ECD centres, the programmes can provide minimum, acceptable and adequate services.

\section{Statement of the Problem}

Observations of ECD centres in Gweru high density suburbs show that they do not resemble the Midlands provincial ECD centre Model Pamberi Nekubatana. Unlike the model centre, the ECD centres do not have the appropriate environment and proper resources which negatively impact on the learners' total development and compromises the ECD programmes. Children need to grow and develop in an environment with resources which nurture them positively. Observation shows that a number of Early Childhood centres in Gweru high density suburbs have inadequate learning resources and environmental space. Most of them have no play centres and are housed in shelters which are unsuitable for Early Childhood learning. The implications of these inadequacies are that ECD children will not develop positively as they scramble for play equipment materials. According to Sheridan and Schuster (2001) quality indoor and outdoor space are important for a quality ECD programme. Provision of resources and environment is imperative for the establishment of an ECD centre. The disparity in the provision of resources and environment between low density ECD centres and high density ECD centres is a cause for concern because it shows inequality in the provision of education. This spurred the need to carry out a research on challenges faced by ECD centres in Gweru high density suburbs in providing resources and environment at their centres.

\section{Research Questions}

The study sought to answer the following questions:

1. What are the resources available in Gweru high density suburb ECD centres?

2. How adequate are the provisions of ECD environment and resources in Gweru high density suburb?

3. Which challenges have ECD centres in Gweru high density faced in terms of providing resources and conducive environment?

4 What can be done to improve provision of resources and environment in Gweru high density suburbs ECD centres?

\section{Significance of the Study}

This study was important in that it focused on resource and environment challenges faced by ECD centres in Gweru high density suburbs. Understanding the challenges faced by ECD centres would unearth vital information useful for the improvement of the quality of the centres. Findings would inform centres on what to do in order to improve standards. Information documented would contribute to better understanding about poorly resourced centres. The findings from the research would inform the Ministry of Primary and Secondary Education on the state of ECD centres in urban high density suburbs. Recommendations made which would hopefully influence policy makers on establishing ideal ECD centres. The findings would also contribute towards promoting resource and environment needs as observed by United Nations Convention on the Rights of Children (UNCRC) (1989). ECD children would receive better service delivery and teachers would realise the reason for utilising resources and the environment.

\section{Literature Review}

\section{Prepared Environment}

This study was informed by Montessori's theory of the prepared environment and relevant resources (Orem, 1965). The theory focuses on the child's physical, intellectual, emotional, moral and social 
development. According to the theory, for children to develop to their full potential, they need a prepared environment and resources both human and material. The theory posits that development of children is affected by interactions and environment. (Rousseau in Ornstein and Hunkins, 2009 Pianta and Kaufman, 2006) comment that the size of the environment and resources affect child development. The prepared environments designed by Montessori were settings such as the classroom, a room or playground with indoor space having different play centres and outdoor with playgrounds with a variety of equipment and gardens.

In her theory, Montessori (2007) came up with the idea of a child-sized environment. Child-sized means that the environment should meet the nature of the child (Lillard, 1996). This is an environment where everything in it is designed to the size of the child. Rousseau in Patterson (2008) argues that a child-sized environment would be ideal because an adult environment is not suitable in terms of size. For this reason ECD centres are expected to be scaled down to the child's size so that children to do their activities without assistance for example, lifting, carrying, reaching and handling object in the environment. Orem (1965) states that the furniture used in the environment should suit the size the child. The furniture should be light, chairs, tables, wash basins, toilet seats, door handles and hooks should be of their size and easy to reach. This would be an ideal and conducive environment for children to play in as they develop. Bogost (2012) observes that the indoor activities should also be spacious.

\section{Didactic Learning Materials}

Central to Montessori's theory are didactic learning materials. These are sensorial materials developmentally appropriate materials which meet the needs and interests of children at different age groups (Montessori 2007). These include rods of different size, geometric solids, wooden and rectangular tablets with rough and smooth surfaces. They enhance maximum exploration and experimentation which is important for child development and refine the child's senses for a life of discovery (Bruce, 2011). Children learn through their senses and observation when they come into contact with real objects.

Koper (2000) also agrees with Montessori on didactic materials. He argues that didactic materials are aides used to facilitate teaching and learning and can be classified in two types namely the teaching materials which are, the teacher (who gives guidance) and learning materials (which are the didactic learning resources). According to Montessori (2007) staff are the teachers whom she referred to as trained directresses who understand child development. Koper and Montessori also concur on the need to train specialist teachers in the area of young children's development. The specialist prepares and selects correct learning materials, arranges the physical environment to support children's development and supervises children playing in the environment so that they development positively.

\section{Concrete Operational Development}

Piaget (1967) in Berk (2007) emphasises that young children learn and development positively as they interact with concrete objects in the environment through sensations or experiences, like smell, taste, visual and tactile. For this reason, there should be effective use of real objects for manipulation by the children. These include blocks, letters, objects for stacking and sorting with a range of materials and textures. This reveals that Piaget observed that the environment and objects are critical in the development of the child. Oketch and Asiachi (1992) contend that availability of resources has great implications in what goes on in the schools today.

\section{Gifts and Occupations}

Another influential philosopher, Froebel in Barker (2003) asserts that the prepared environment and resources (gifts and occupations) similar to Montessori create an atmosphere that stimulates child development with the teacher giving guidance. He referred to the didactic materials as gifts which provide hands-on experiences and that teachers are to serve as gardeners of the children. Furthermore 
Rousseau in Ornstein and Hunkins (2009) see the child like a plant in the garden who needs nurturing just like a plant needs watering, pruning and weeding for it to grow and flourish. According to the study, providing the child with materials like books, puzzles, blocks and a variety of other materials which are non-toxic would help to facilitate child development.

\subsubsection{Appraisal of the theories}

Some of Montessori's ideas about child-sized environment which are child-sized furniture and specialised teachers have been incorporated in the Zimbabwean ECD programmes (Lillard and Quest 2006). The Zimbabwean curriculum is eclectic as it borrows ideas from different curriculum models. An ECD in the model of Montessori's theory of a prepared environment and didactic materials is difficult to produce in the third world like Zimbabwe faced with a harsh economic environment. This is because the Montessori theory advocates for the restructuring of an ECD centre to resemble reality in every aspect which requires a lot of finance. This research looked at ECD centres modelled according to some ideas by Montessori's theory considering both indoor and outdoor space. In light of this framework, the researcher was influenced to analyse resource and environment challenges faced by Gweru low density ECD centres. Despite the criticism made, the theory has been found to be useful and many ECD centres in Zimbabwe are modelled on the theory.

Piaget's age stage theory and Froebel's theory of gifts and occupations were also criticised. Cherry (2015) comments that Piaget was criticised for his belief that children's manipulation of objects was essential for normal cognitive development. Similarly, Robson (2004) indicated that Froebel's gifts and occupations prescribed were also criticised as they catered mostly for fine motor skills. The manipulative materials, gifts and occupations were adopted in the Zimbabwean ECD programme in the form of concrete objects. These are educational learning materials (building blocks and other play materials) or didactics tools stated by Montessori to facilitate learning development. This means that the ECD centres would have to be adequately equipped with these material resources in order to facilitate teaching and learning

\section{International Legal Frameworks on Early Childhood Development}

Early Childhood Development Education (ECDE) has been supported by a number of international legal frameworks. The Dakar Framework for Action on Education for all (2000) Goall emphasised the need to expand and improve comprehensive early childhood care and education especially for the most vulnerable and disadvantaged. According to Haque, Rahman, Begum and Hamid (2013) the United Nations Convention on the Rights of Children (UNCRC) (1989 Article 4) declares that the international policy supports both the rights of the child and the obligations by the state, society, and international community. The Convention on the Rights of the Child (CRC) (1959) article 4 also stipulates that the government's responsibility is to help create an environment where children can grow and reach their potential.

\subsubsection{Millennium Development Goals Framework}

The Millennium Development Goals (MDG'S) Goal Number 2 focuses on the achievement of Universal Primary Education (UPE) by 2015. Its aim was to ensure that all children regardless of gender should be able to complete a full course of primary education. This goal focuses on issues pertaining to children's education. For the goal to be achieved there is need for a suitable environment and relevant resources to secure quality education at infancy. Of particular concern are the centres in which ECE programmes are being enforced.

Subsequent international agreements such as the Jomtein Conference World Conference (1990) on Education for All (EFA) nations present agreed to take necessary action to universalize quality ECD education for young children. This led to the resolution that all children should have access to education which made education a fundamental right to all children in the world. According to Mustard (2006) the deliberations of the conference emphasised that the first six years of life are 
extremely important because the experiences in the environment during this period are significant influencing one's life. As a result the resource and type of environment are crucial as ECD was recognized as a critical time and window period of development as observed by Montessori (2007).

To support the ECD programme on resource and environment needs, United Nations Children's Emergency Fund (UNICEF) (2006) set guidelines for Early Childhood Development Services which stipulate the minimum standards for resource and environment at ECD centres. The guidelines give specifications on child-space ratio, indoor $1: 1,5 \mathrm{~m}^{2}$ and outdoor $2 \mathrm{~m}^{2}$ and those ECD children should not share toilets with upper grades and staff. These are meant to assist governments on the type of environment and resources that would be needed to run an ECD centre and bring about UPE. The guidelines provide for the regulations of the standard operating procedures for ECD centres with regards to the physical environment, various indoor and outdoor areas, facility-learner ratios and resources among other needs for centres to operate to full capacity. The materials resources and environment are important in ECD programs as quality services are appropriate for stimulation of physical, intellectual, emotional and social development during sensitive periods as observed by Montessori.

\section{The Zimbabwean Early Childhood Development National Framework}

Zimbabwe as a participant and signatory of the above international policy frameworks has shown its preparedness to implement ECD centres by promulgation of policies and circulars which support ECD programmes. It has also promulgated some policies to enforce and guide the implementation of ECD programmes in Zimbabwe. One of the administrative tools used in the ECD programme is the Secretary's Circular 14 of 2004. It stipulates guidelines of implementation of ECD "A" and "B" as recommended by Nziramasanga (1999). Statutory Instrument 106 of 2005 provides specifications on how ECD centres should operate and be structured. It specifies that playing space ratio per child should be 2,25square metres for indoor activities and 5,5 square metres for outdoor activities . Directors' Circular 48 of 2007 spells out that centres are required to use locally produced materials for teaching and learning because of diverse cultures in Zimbabwe. The Directors' Circular 12 of 2005 on the other hand gives details on what should be done at ECD centres and states the guidelines on the provisions of ECD in the primary school (public centres) and private centres.

\section{Early Childhood Development in the West Bank and Gaza}

A study on resource and environment challenges faced by ECD centres was carried out in West Bank and Gaza by an organisation called the American Near East Refugee Aid (ANERA) on improving lives in the Middle East (2014). ANERA's report revealed that access to primary education was not supported by national frameworks or public financing leading to gaps in service delivery that affect environment and resource. Observations made showed that environment was not designed to suit child care which had a negative effect on the child development. The study observed that in terms of resources, the playground equipment were in short supply. The Ministry of Primary and Secondary Education did not have adequate financial and human resources. The results also revealed that there were inexperienced ECD teachers and limited parental involvement. In terms of teaching methods, ECD centres in these areas were seen to rely on rote learning. In relation to environment it was observed that there were inadequate facilities at the ECD centres. There was lack of trained teachers at the centres and effort was made to train them.

\section{Early Childhood Education in Botswana: A Case of Fragmented "Fits"}

In Botswana, a study carried out by Maunganidze and Tsamaase (2013) indicated that there are no clear guideline to provide standardisation in the provisions of Early Childhood Care and Education (ECCE). ECD programmes in Botswana are operating with diverse ranges determined by the owner of the centre. There is no policy which standardises the implementation of ECD in the country. This leads to differentiated educational provision of ECE since children are not exposed to the same type of education. Maunganidze and Tsamaase (2013) also argue that policy on ownership of ECCE 
programmes is relaxed and owners choose how they want to run their centres resulting in to failure to meet UPE. Bose (2008) also observed that because of the relaxation of policy on ECD centres in Botswana. It was observed that there was a high teacher to pupil ratio. There was also lack of adequate training centres and shortages of suitably trained and qualified personnel in public centres (Republic of Botswana, 2001). Privileged children of elite had access to centres with trained personnel and adequate resources. Equality in terms of provision of educational resources at ECD level cannot be realised because of the fragmented approach to implementation of ECE in the country.

\section{Challenges facing the early childhood development sector in South Africa}

Atmore, Nierkerk and Cooper (2012) carried out a study on challenges facing the ECD sector in South Africa. The study revealed that there were great differences based on resource and environment based on racial inequalities in South African ECD centres. ECD centres for the black learners were recorded as below average ratings on infrastructure quality measured against the guidelines of setting up ECD centre on resource and environment when compared to EDC centres for white learners (Department of Education, 2001).

Research findings also reveal that ECD centres for blacks operate in improvised locations, houses or parts of a house and others from shacks. The varied ECD centres sites bring about differences in the kind of services provided which in turn affect the goal to reach UPE. Further observations in the research on ECD centres in South Africa revealed that some ECD centres required urgent maintenance. This was risk for the children who attended these centres thereby compromising effective implementation of the ECD programme. The situation in South Africa resembles the situation under study. Provision of resources and environment in ECD centres in Gweru Urban reflect differences between affluent low density residents and working class residents in high density suburbs. Provision of ECD requirements in these residential areas is based on affordability of the residents to pay for the services and resources of their children. Most ECD centres in High density suburbs can be rated below average ratings on infrastructure quality required for ideal ECD centres.

\section{Challenges faced by ECD centres at satellite schools in Mwenezi District, Zimbabwe.}

Takesure, Moses, Christmas, Kudzai and Emily (2013) carried out a study to identify challenges in successful implementation of ECD curriculum in satellite schools in Mwenezi District. The ECD centres were established under the Zimbabwe Land Reform Programme upon its inception in 2000. The study revealed that satellite schools faced serious challenges notably lack of suitable teaching and learning resources, understaffing, high teacher-child ratio, inappropriate medium of instruction and responsiveness of the community. The state of infrastructure, classrooms and ablution facilities ranged from huts made of pole and dagga to dilapidated old farm house. The research also noted gross unavailability of suitable playground and equipment. The study concluded that the state of the ECD centres was a critical area of concern which needed urgent attention.

A study by Kuyayama (2013) on the capacity of ECD policy and reports in promoting inclusive education in Zimbabwe revealed that ECD centres require resources and stimulating environments for all round child development. There is need for positive nutrition, health and safety should be taken into account as stipulated in Director's Circular No. 48 of 2007 and Statutory Instruments 106 of 2005 respectively.

\section{Methodology}

This study was a descriptive survey which used both of qualitative and quantitative methods of collecting data to answer the same questions adopted a mixed method approach. Cohen, Manion and Morrison (2012) contend that a descriptive survey in collecting data describes issues concerning the status of the subject under study concerning the current issues Descriptive surveys describe natural phenomena which reveal underlying issues relevant in educational research. The study looked at ECD centres in their natural states. Hancock, Windridge and Ockleford (2009) contend that the advantage 
with survey is that it can be used to collect a lot of data with relatively small expenses The study was carried out in sixty (60) ECD centres in Senga, Mambo, Ascot, Woodlands and Mkoba high density suburbs. The centres comprised of fifteen (15) public centres and forty-five (45) private centres. Twenty-seven (27) ECD teachers were purposively sampled to take part in the study. Paly and Atchison (2008), Cohen, et al (2012), McMillan and Schumacher (2010), state that purposive sampling is used to select people with the required knowledge of the study. In-depth interviews, questionnaires, observations and document analysis were used to collect data. Morse (1991) argues that this methodological triangulation of collecting data helps to come up with credible results.

\section{Findings}

\section{Teacher-Pupil Ratio}

Teacher- pupil ratio has a role in lesson delivery by the teacher. The following table shows the teacher people ratio in ECD centres of Gweru Urban High density suburb.

Teacher to Pupil Ratio in ECD Centres

\begin{tabular}{|l|c|c|c|c|c|c|c|}
\hline Centre & A & B & C & D & E & F & Average \\
\hline $\begin{array}{l}\text { Number of ECD A } \\
\text { children }\end{array}$ & 50 & 0 & 15 & 10 & 13 & 0 & 15 \\
\hline $\begin{array}{l}\text { Number of ECD B } \\
\text { children }\end{array}$ & 50 & 100 & 117 & 33 & 46 & 154 & 83 \\
\hline Number of teachers & 2 & 4 & 3 & 1 & 1 & 4 & 3 \\
\hline Ratio & $1: 50$ & $1: 25$ & $1: 44$ & $1: 43$ & $1: 59$ & $1: 39$ & $1: 33$ \\
\hline
\end{tabular}

The table shows that all the ECD classes had a teacher-pupil ratio which was more than the recommended 1:20. This had an effect of poor lesson delivery by the teacher. Because of the large class, the teacher could not attend to the individual needs of the learners. Cobb (2001) argues that it is difficult to manage and supervise high numbers of children as there would be lack of flexibility to cater for children's needs and interests. The above data revealed that the classes were too large for ECD programme to succeed. This could be a result of shortage of ECD centres in the high density suburb. This was worsened by the fact that the few available centres do not have adequate classrooms. As a result, ECD 'A' learners and ECD 'B' were combined in fifty-nine percent (59\%) of the centre. The recommended approach is to have separate classes. Cherry (2015) argues that mixing age groups in not an ideal ECD set up because of the different developmental levels, needs and interests of these age groups which may not or never be achieved positively. 
Figure: 4.5 ECD A and B centre enrolment status by centres

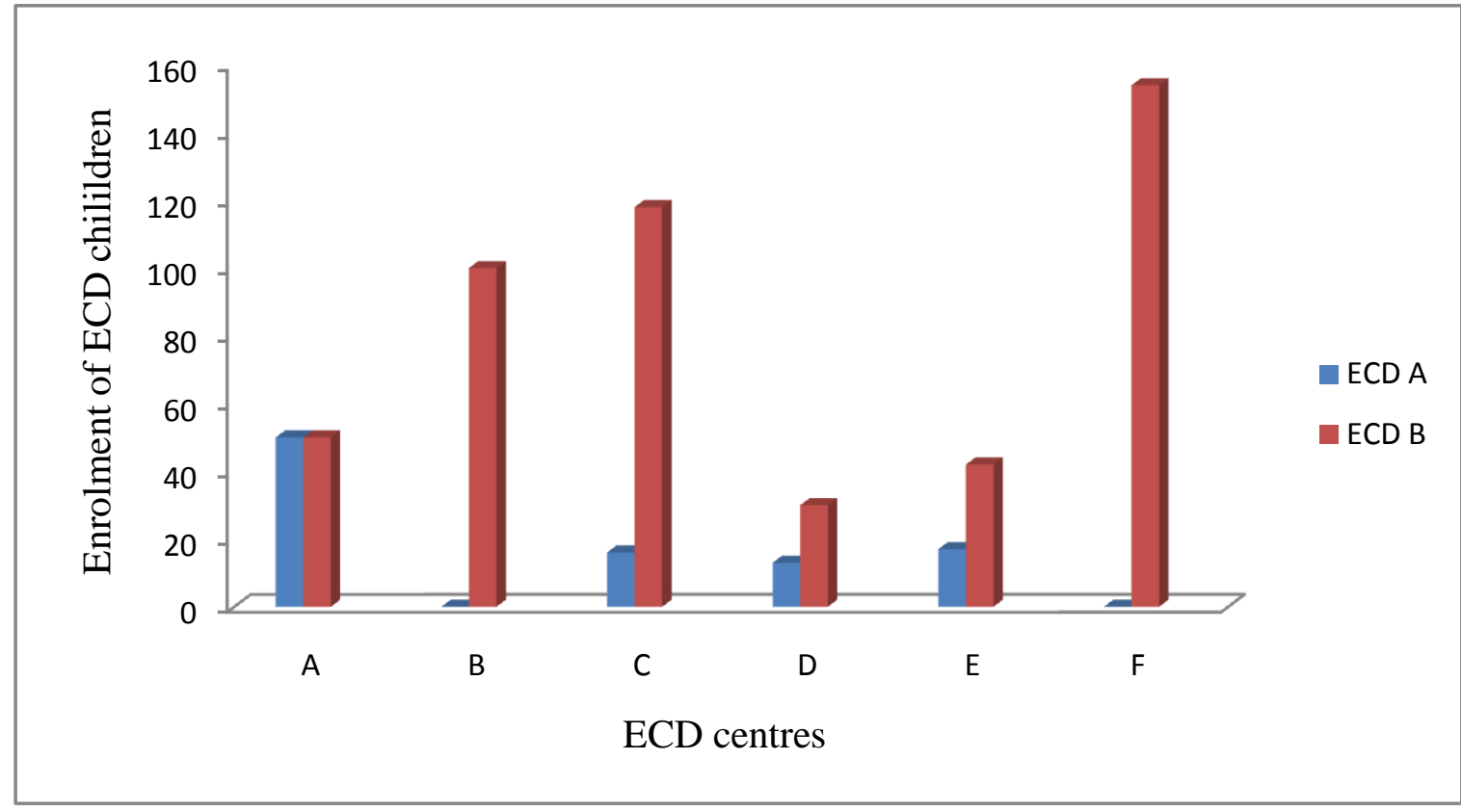

An observation checklist was also used by the researchers on the enrolment of ECD A and B children per centre. Figure 4.5 revealed that sixty-seven percent (67\%) had both ECD A and B whilst thirtythree percent (33\%) have ECD B only. The centres which did not have ECD A and B showed that they were not meeting the requirements of the Secretary's Circular 14 of 2004 which states that ECD children should go through the two year programme before starting grade one. The children from centres which do not offer ECD A may develop a learning gap because of not attending the two year programme.

The study also assessed the availability of outdoor equipment at the centres. The following table shows statistics of the equipment:

Table 4.2 Availability of Outdoor Equipment at ECD Centres (N=6)

\begin{tabular}{|l|l|l|l|l|l|l|l|l|l|l|}
\hline Centre & SW & SS & SL & CL & MGR & BB & TH & SP & B & T \\
\hline A & 2 & 0 & 1 & 0 & 0 & 0 & 0 & 1 & 0 & 0 \\
\hline B & 2 & 0 & 0 & 1 & 0 & 0 & 0 & 1 & 1 & 1 \\
\hline C & 1 & 1 & 1 & 1 & 0 & 0 & 0 & 1 & 2 & 0 \\
\hline D & 1 & 1 & 0 & 0 & 0 & 0 & 0 & 1 & 0 & 0 \\
\hline E & 1 & 1 & 1 & 1 & 0 & 0 & 0 & 0 & 0 & 0 \\
\hline F & 4 & 3 & 2 & 1 & 0 & 0 & 0 & 0 & 0 & 0 \\
\hline Total & 11 & 6 & 5 & 4 & 0 & 0 & 0 & 4 & 3 & 1 \\
\hline Average & 2 & 1 & 1 & 1 & 0 & 0 & 0 & 1 & 1 & 0 \\
\hline
\end{tabular}


Key: $\mathrm{SW}=$ Swings; $\mathrm{SS}=$ See Saw SL $=$ Slides $; \mathrm{CL}=$ Climbers $;$ MGR $=$ Merry-go-round $\mathrm{BB}=$ Balancing beams; $\mathrm{TH}=$ Tree house; $\mathrm{SP}=$ Sandpit; $\mathrm{B}=\mathrm{Bus} ; \mathrm{T}=$ Truck

Table 4.2 shows that four (4) centres had see-saws, however, there were not enough considering the high enrolment in the centres. One third of the centres had no slides, pit sand, merry-go-round, climbers and see-saws. All the centres did not have merry-go-round, tree house and balancing beams which are also recommended for the holistic development of the children. The centres had inadequate equipment to serve the number of children at the centres. The Ministry of Primary and Secondary Education recommends that ECD play centres should have ten children to one swing. Kenny (1997) states that well-funded ECD programmes are able to provide adequate equipment for children to play thereby fulfilling their need to play freely and develop without limitations. Thus, not all the children would benefit from the equipment whenever they wanted to

\section{Adequacy of indoor resources at the centres}

The study assessed asserts registers and observed indoor resources at the centres to ascertain the adequacy of indoor for learners at the centres. The following table shows the availability of indoor resources at the centres.

\section{Adequacy of indoor resources $(\mathrm{N}=6)$}

\begin{tabular}{|c|c|c|c|c|c|c|c|c|c|c|c|c|c|c|c|c|c|c|}
\hline \multirow[t]{2}{*}{ Centre } & \multicolumn{3}{|c|}{ Toys } & \multicolumn{3}{|c|}{ Dolls } & \multicolumn{3}{|c|}{ Blocks } & \multicolumn{3}{|c|}{ Small Drums } & \multicolumn{3}{|c|}{ Puzzles } & \multicolumn{3}{|c|}{ Easels } \\
\hline & 0 & 1 & 2 & 0 & 1 & 2 & 0 & 1 & 2 & 0 & 1 & 2 & 0 & 1 & 2 & 0 & 1 & 2 \\
\hline A & & $X$ & & & $X$ & & & & $\mathrm{X}$ & $\mathrm{X}$ & & & $X$ & & & $X$ & & \\
\hline $\mathrm{B}$ & & $\mathrm{X}$ & & & & $\mathrm{X}$ & $\mathrm{X}$ & & & & $\mathrm{X}$ & & & $\mathrm{X}$ & & $\mathrm{X}$ & & \\
\hline $\bar{C}$ & & $\mathrm{X}$ & & $\mathrm{X}$ & & & & $\mathrm{X}$ & & $\mathrm{X}$ & & & & $\mathrm{X}$ & & $\mathrm{X}$ & & \\
\hline D & $\mathrm{X}$ & & & & $\mathrm{X}$ & & & $\mathrm{X}$ & & $\mathrm{X}$ & & & $\mathrm{X}$ & & & $\mathrm{X}$ & & \\
\hline $\mathrm{E}$ & & & $\bar{X}$ & & & & $\mathrm{X}$ & & & $\mathrm{X}$ & & & $\mathrm{X}$ & & & $\mathrm{X}$ & & \\
\hline $\mathrm{F}$ & & $X$ & & & $X$ & & $\mathrm{X}$ & & & $\mathrm{X}$ & & & & $\mathrm{X}$ & & $X$ & & \\
\hline
\end{tabular}

KEY: 0 = Non; $1=$ inadequate; $2=$ adequate

The table reveals that all centres had inadequate indoor teaching materials for children to play with as observed by Froebel. Evidence reveals that there is no centre which is well equipped with the standard indoor materials expected as evidenced by the distribution on the table of what was recorded. Piaget (1967) in Berk (2007) believed that reasoning deepens in children as they are engaged in the physical and social world. Children's development is stimulated by interaction with objects in the environment some of which were observed and recorded in Table 4.3. Eighty-three percent (83\%) of the centres had no drums and all the centres showed that they did not easels meant for art lessons.

A teacher from one of the centres indicated that the toys at their centre were donated by parents and the children take them back home at the end of the year. However, children whose parents did not donate toys had nothing to play with. These results showed that there were challenges of acquiring indoor and outdoor equipment by high density ECD centres in Gweru. The net effect of this shortage was improper development of skills by learners and smooth running of the centres. Availability of child-sized outdoor play equipment and indoor materials were the indicators of the standard and quality of ECD centres as sampled by the Pamberi Nekubatana Model Centre. ECD centres should therefore be well equipped with requisite ECD equipment. 
Availability of child-sized equipment at centres

\begin{tabular}{|c|c|c|c|c|c|c|c|c|c|c|}
\hline Centres & $\mathrm{CH}$ & $\mathrm{R}$ & $\mathrm{B}$ & $\mathrm{R}$ & $\mathrm{TA}$ & $\mathrm{R}$ & $\mathrm{TO}$ & $\mathrm{R}$ & $\mathrm{CO}$ & $\mathrm{R}$ \\
\hline $\mathrm{A}$ & 0 & 0 & 50 & $1: 2$ & 50 & $1: 2$ & 0 & 0 & 7 & $1: 14$ \\
\hline $\mathrm{B}$ & 0 & 0 & 52 & $1: 2$ & 52 & $1: 2$ & 0 & 0 & 0 & 0 \\
\hline $\mathrm{C}$ & 44 & $1: 3$ & 0 & 0 & 22 & $1: 6$ & 4 & $1: 33$ & 0 & 0 \\
\hline $\mathrm{D}$ & 43 & $1: 1$ & 0 & 0 & 22 & $1: 2$ & 0 & 0 & 0 & 0 \\
\hline $\mathrm{E}$ & 59 & $1: 1$ & 0 & 0 & 30 & $1: 2$ & 0 & 0 & 0 & 0 \\
\hline $\mathrm{F}$ & 154 & $1: 1$ & 0 & 0 & 77 & $1: 2$ & 7 & $1: 22$ & 0 & 0 \\
\hline $\mathrm{X}$ & 50 & & 51 & & 42 & & 2 & & 1 & \\
\hline SD & 1,7 & & 2,1 & & 0,8 & & 1,25 & & 0,23 & \\
\hline
\end{tabular}

KEY: $\mathrm{CH}=$ Chairs; $\mathrm{B}=$ Benches; $\mathrm{TA}=$ Tables; $\mathrm{TO}=$ Toilets; $\mathrm{C}=$ Computers; $\mathrm{R}=$ Ratio; Mean $=\mathrm{X}$; Standard Deviation $=$ SD

The table shows the ratios of child-sized materials per centre and Standard Deviation (SD). The mean and the standard deviation were greatly affected by outliers. The standard deviations (SD) for chairs and benches were 1, 7 and 2, 1 respectively. These standard deviations were large and mean that there are further away from the mean. This meant that there was a large variation in terms of provision of tables and chairs in high density ECD suburbs. They ranged from 0 to 154 for chairs and 0 to 50 for benches. The provisions for chairs did not differ much. Sixty-seven percent $(67 \%)$ of the centres use chairs and thirty-three percent (33\%) do use benches. Centres with benches, had a larger SD scattered away from the mean though use of benches is not recommended.

Adequacy of resources, appropriateness of physical environment and challenges faced by the centre

Decision on adequacy of resources, appropriateness of physical environment and challenges faced by the centres was determined by the mean responses to questionnaires. Nominal values of, Strongly Agree (SA) 4, Agree (A) 3, Disagree (D) 2 and Strongly Disagree (SD) 1 were calculated:

$$
\frac{4+3+2+1}{4}=\frac{10}{4}=2.5
$$

(Adopted: Azubuike and Offordile, 2011)

An interval scale of 0.5 was added to give a mean of 3 . The total number of responses were multiplied as per rating then divided by total number of respondents. Responses of 3 and above were considered as agree and those below 3 were considered as disagree

\begin{tabular}{|l|l|l|l|l|l|l|l|}
\hline Item. & SA & A & D & SD & N & $\mathbf{X}$ & Decision \\
\hline Resources are inadequate environment is & 16 & 8 & 4 & 2 & 30 & 3.3 & Agree \\
\hline $\begin{array}{l}\text { Physical } \\
\text { inappropriate }\end{array}$ & 30 & - & - & - & 30 & 4 & Agree \\
\hline $\begin{array}{l}\text { Centres have challenges acquiring } \\
\text { resources and providing suitable } \\
\text { environment }\end{array}$ & 23 & 7 & - & - & 30 & 3.7 & Agree \\
\hline
\end{tabular}

Results from the table indicated that respondents agreed that the resources in the centres were inadequate. Because resources were inadequate in many centres, pupils scrambled for them which 
might be a safety risk. The inadequacy of these resources also compromised the development of the child physically, socially, emotionally and intellectually. This is supported by Riley (2007) who maintains that material resources promote developmental opportunities for children. Consequently there is need for materials which are age appropriate and enable children to explore and learn positively. Results ECD centres under in Gweru high density suburbs were lacking in this aspect. Inadequate equipment did not afford children opportunity to enjoy and play effectively because they had to wait for others.

\section{Discussion of Findings}

From the study it emerged that many centres in Gweru High Density suburbs do not have adequate resources. These include chairs, benches, tables, computers and toilets. The provision of educational resources in the centres is below the standard requires by Instrument 106 of 2005. This has negative impact on the learning of ECD pupils in High density suburbs. Most of them do not meet regional ECD model Pamberi Nekubatana. All the centres have a teacher pupil ratio of more than the required 1:20. To make matters worse, most centres are manned by trainee teachers, unqualified teachers and teachers who did not specialise in ECD. There is need to ensure that the centres have well trained teachers adequate and resources. The Ministry of Primary and Secondary education should intervene and make sure that centres meet the required standards.

The study also revealed that some centres are inappropriately located. Houses are turned into centres and there is inadequate space and equipment. Observation showed that these centres are run as commercial centres where individuals just want to establish centres in order to get money through payment of fees but do not invest the money sourcing the required equipment and resources. This is indicative of the fact that these centres are allowed to operate without meeting required standards. This explains the differential performances of ECD students in High density suburbs and low density suburbs in Gweru.

\section{Conclusion}

Inadequate provision of suitable human and material resources is a major handicap in high density ECD centres. Most of them do not have trained personnel. Most of the residents in high density suburbs are low income earners and cannot pay high fees for EDC education. As a result the levies raised cannot purchase the required equipment for the centres. There are also inadequate ECD centres in high density suburbs. This resulted teacher pupil ratios which were far ahead of the stipulated teacher pupil ratio.

\section{Recommendations}

In view of the findings and conclusions on the resource and environment challenges faced by ECD centres in the Gweru high density suburb, the study made the following recommendations;

5.4.1 That the government and local council should provide free land for the establishment of ECD centres for both private and public ECD centres. This will enable centres to have required environment for ECD centres.

5.4.2 The Ministry of Primary and Secondary Education should consider allocating a special budget for early childhood learning. This will allow proper funding for ECD centres and ensure acquisition of required equipment. Adequate provision of resources will ensure full development of learners' potentials.

5.4.3 The Ministry of Primary and Secondary Education should not allow ECD centres to operate with limited resources and a prepared environment. This ensures that ECD centres operate with requisite equipment thereby preparing the child to acquire required skills. With adequate materials children can realise their full potential according to Montessori framework of ECD centres. 
5.4.4 Schools should initiate and engage communities to participate in income generating projects to fund and support the ECD centres. This would fulfil what the Secretary Circular No 14 of 2004 which states that ECD being a community based programme. Participation of communities empowers the communities to have ownership and interest in their centres.

5.4.5 Teachers without specialisation in ECD training should undergo in-service training inorder to acquire relevant skills and knowledge to manage ECD classes. This will help to ensure that pupils will benefit from teaching.

\section{References}

1. Atmore, E, van Niekerk, L. and Ashley-Cooper, M. (2012) Challenges facing the early childhood development sector in South Africa. South African Journal of Childhood Education, 1(2): 121-140.

2. Barker, R. (2003) Philosophies of Education: An Introductory Course. Harare: College Press.

3. Berk, L. E. (2007) Child Development; New Delhi: Prentice Hall India (Pvt) Ltd.

4. Bernard, H. R. (2005) $2^{\text {nd }}$ edition. Research Methods in Anthropology. London: Sage Publications.

5. Bogost. I, (2012) Alien Phenomenology or What it's like to be a thing. Minneapolis: University of Minneapolis Press.

6. Bose, K. (2008) Early childhood care and education programmes in Botswana: Policy (2001) implementation. Asia-Pacific Journal of Research in Early Childhood Education, 2, 3-23.

7. Bredekamp, S. and Coople, C. (1997) Developmentally Appropriate Practices in Early Childhood Programmes. Washington; DC: National Association for the Education of Young Children.

8. Bruce, T. (2004) Developing learning in Early Childhood. London: Paul Chapman.

9. Bruce, T. (2011) $4^{\text {th }}$ edition. Early Childhood Education. London: Hodder Edu.

10. Chaube, S.P. and Chaube, A. (2003) School Organization. New Delhi: Vikas Publishing house PVT Ltd.

11. Cobb, N.J. (2001) The Child. London: Mayfield.

12. Cohen, L., Manion, L. and Morrison, K. (2012) Research Methods in Education: New York: Routledge Falmer.

13. Convention on the Rights of Children (1959): United Nations.

14. Director's Circular No 48 of 2007. Implementation of the ECD programme in the primary schools and in privately-owned and run centres. Harare: Government Printers.

15. Director's Circular No. 12 of 2005. Implementing Early Childhood Development Education Development Education Programme in Schools and Centres. Harare: Ministry of Education, Sport, Arts and Culture.

16. Hancock, B., Windridge, K. and Ockleford, E. (2009) An Introduction to Qualitative Research. Yorkshire: The NIHR Research Design Service.

17. Haque, M.A., Rahman, M.F., Begum, H. and Hamid, A. (2013) Qualitative survey assessing impacts from Cyclone Sidr and Aila on the communities of Koyra and Gabura: Bangladesh.

18. Kenny, S. (1997) Music in developmentally appropriate curriculum, in integrated curriculum and developmentally appropriate practice: Birth to age eight. Albany; NY: University of New York.

19. Koper, R. (2000) From change to renewal Educational technology foundations of electronic learning Enviroments. http://hdl.handle.net/1820/38. Accessed 20-09-15.

20. Kuyayama, A. (2013) The capacity of Early Childhood Development Policy and Reports in Promoting Inclusive Education in Zimbabwe: The Zimbabwe Gabtus Journal of Teacher Education ZIJET Volume.15 (2) ISSN 1022-3800.

21. Lillard, A.S. and Quest, N.E. (2006).The Early Years: Evaluating Montessori Education. Science 313:1893-94.

22. Lillard, P. (1996) Montessori Today. New York: Schochen Books. 
23. Maunganidze, L. and Tsamaase, M. (2013) Early Childhood Education in Botswana: A Case of Fragmented "Fits," Volume 7, Number 5.

24. McMillan, J.H. and Schumacher, S. (2010), Research in education: Evidence Based Inquiry. $7^{\text {th }}$ Edition: New Jersey: Pearson.

25. Montessori, M. (2007) Doctor Montessori's Own Handbook: illustrated. Chicago: BN Publishing.

26. Morse, J.M. (1991) Approaches to qualitative-quantitative methodological triangulation: Nursing Research, 40, 120-123.

27. Mugweni, R.M. (2011) Review of the Education Transition Fund and Early Childhood Development Sub-Sector Analysis. Harare: Unpublished Commissioned Research Report.

28. Mustard, J.F. (2006) Early Childhood Development And Experienced-based Brain Development: The Scientific underpinning of the importance of ECD in a Childhood global world. Washington; DC: Brookings Institution.

29. Nziramasanga, C.T. (1999) Report of the Presidential Commission of Inquiry into Education and Training. Harare: Government Printers.

30. Oketch, J.G and Asiachi, A. (1992) Management in Education. Nairobi: Education Research and Publication.

31. Orem, R.C. (1965) A Montessori Handbook. New York: G.P. Putman's Sons.

32. Ornstein, A. C \& Hunkins, (2009) Curriculum, Foundations, Principles and Issues. London: Allyn and Bacon.

33. Paly, T\& Atchison, C. (2008) Research decisions: Quantitative and Qualitative perceptive. Toronto: Thomson Nelson.

34. Patterson, T. (2008), Child Development. New York: Worth Publishers.

35. Pianta, R.C. and Kaufman, S.R. (2006) The Social Ecology of the Transition Classroom, Families and Children: Blackwell Handbook Early Childhood Development. Malden:USA: Blackwell publishing.

36. Republic of Botswana, (2001) Early Childhood Care and Education Policy-2001: Gaborone: Government Printers.

37. Riley, J. (2007) Learning in early years 3-7: London: Sage Publishers.

38. Robson, S. (2004) Developing thinking and understanding in young children. Oxford: Routledge.

39. Secretary's Circular No. 14 of 2004 Implementing Early Childhood Development Education Development Education Programme in Schools and Centres Harare. Ministry of Education Sport and Culture.

40. Statutory Instrument 106 of 2005: Early Childhood Development Centres Regulations; Harare: Government Printers.

41. Study guide for GGE100-B (1993) Geographical Perspective and Analysis. Pretoria: University of South Africa.

42. Takesure, H., Moses, K., Christmas, D., Kudzai, C. and Emily, G. (2013) Challenges faced by ECD centres at satellite schools in Mwenezi District, Zimbabwe; European Journal of Educational Sciences, 1(3): 108-115.

43. United Nations Children's Emergency Fund (UNICEF) (2006) Evaluation of the national early childhood development programme. Harare: Ministry of Education.

44. United Nations (1989) United Nations Convention on the Rights of the Child (UNCRC) Geneva: United Nations.

45. The Draft National ECD Standards. (2013) Zimbabwe Network of Early Childhood Development Actors (ZINECDA) (2013) Harare: Government Printers. 